\title{
Evaluation of Good Financial Health Management Practices and its contribution to Program Implementation Rate for Small NGOs Supported by Donors in Malawi
}

\author{
Article by Jones Stevelio Stamalevi, Malawi \\ Executive MBA, Texila American University, Rwanda \\ Email:stamalevi@yahoo.com
}

\begin{abstract}
Financial health management practices involves the management of the six key variables according to this research work which includes budgeting and planning, accounting system, internal control, financial reporting, grant management and staffing. Most nongovernmental organizations (NGOs) do not manage these variables and this has been a major obstacle to their programs implementation rate.

The study evaluates the effects of financial health management practices on implementation rate for NGOs. The study utilized a diagnostic research design and it's a single case study targeted Malawi Girl Guide association (MAGGA) one of the NGO listed and registered in Malawi. Data was obtained through questionnaire and from document analysis of consolidated financial reports of years ending December: 2010, 2011, 2012 and 2013. Both qualitative and quantitative analyses were carried out on the data to determine the relationships between components of financial health management practices and the program implementation rate of the NGO.

The study established that financial health management practices was strongly related to high implementation rate. Implementation rate of an NGO depends upon effective financial health management practices. Furthermore, contrary to the expectation of the researcher, the research has further established that donors also contribute to poor implementation rate by late funding the NGOs supplemented by lack of program monitoring visits, spot check and lack of capacity building for implementing NGOs. These are the major constraints the NGOs face when implementing donor funded programs. The study therefore recommended that NGOs should focus on strengthening financial health management practices and encourage donors to disburse funds on time and make sure to carry out assurance activities like program monitoring, spot check visits, auditing and capacity building to minimise financial risks.
\end{abstract}

Keywords: Planning and Budgeting; Accounting system, Grant management, Internal Control; Financial Reports, Staffing, Implementation rate, Nongovernmental Organization.

\section{Introduction}

\section{Background}

Non-Governmental Organizations (NGOs) have existed in many forms over centuries. In developing countries where they appear to be needed most they are progressively receiving more significant recognition as the 'third sector'. NGOs are now increasingly and uniquely recognized by statute in a most countries. Traditionally non-profit organizations in the Commonwealth have been able to establish themselves mainly and simply as legal entities such as trusts or companies limited by guarantee. However in the past two decades a variety of legislation has been introduced in a number of countries setting out standards which they should follow, some of which has been controversial.

Tvedt observed that NGO is a term "for all organizations within the aid channel that are institutionally separate from the state apparatus and are non-profit-distributing. " (ibid. 12)Tvedt specifies that 'to be within the aid channel' means that the organization gets funding from the aid system; those organizations that get funding are in, and those that do not, are out (Tvedt 1998, 12; Tvedt 2006, 685). These boundaries are material boundaries, largely controlled by donors and they may shift according to the donor policies (Tvedt 2006, 685). 
The NGO Board of Malawi is a Statutory Body established by section 6 of Non-Governmental Organizations Act (Cap 5:05 of Laws of Malawi) to register and regulate the operations of all NGOs in Malawi. The NGO Act was passed in Parliament and assented by the 27th January, 2001. All NGOs activities in Malawi are currently coordinated through the Office of the President and Cabinet (OPC)

The Non-Governmental Organization Act, which was introduced in 2001 as stated above, requires that all international and national NGOs working in Malawi register with the Council for NonGovernmental Organizations in Malawi (CONGOMA) and the NGO Board of Malawi. CONGOMA is a designated NGO coordinating body in Malawi as stipulated in Section 24 and 25 of the Nongovernmental Organizations Act 2000. Membership to CONGOMA is open to National and International NGOs and is responsible for representing and promoting the collective interest of NGOs in Malawi.

\section{Role of NGO in malawi}

Malawi is one of the least developed countries in the world, the role that NGOs and civil society organizations play in the country's development is invaluable. Numerous NGOs work throughout the country across a variety of areas, including health, education, women's rights and rural development.

NGOs have played an important role in furthering democracy and human rights, social and economic development, and nation-building. In October 2005, Andrew Galea Debono of the Commonwealth Human Rights Initiative noted that while it is true that many NGOs, the media, academics and many other community groups focus primarily on providing services to the community, experience has shown that they have also often been key facilitators of governmentcitizen dialogue as well as having an important monitoring role of government activities.

NGOs have also earned a reputation for playing a vital role in being the voices of the voiceless in Malawi and have helped to consolidate a democratic culture in the country since the institution of multi-party democracy in 1994 by providing checks and balances against governmental corruption like the recent cash gate scandal where billions of money were lost due to weak internal controls in the government system. Their contributions also have been seen in areas such as health, education, and environment. Those in arts and culture have also played a critical role in safeguarding and preserving Malawi's identity, while those in human rights have made strides in raising community awareness against negative cultural traditions and beliefs such as child marriages and witchcraft.

\section{Pressure faced by NGOs}

Due to the watchdog roles some NGOs play in Malawi and elsewhere, NGOs have on many occasions turned out to be among the government's fiercest critics, and at times government officials have labeled them as an "opposition" force. Such acrimony has resulted in a number of civil society activists working in a very politically sensitive environment, with numerous incidences of threats, physical and emotional harassment.

The current government announced in September 2014 that it would prioritize the review of Malawi's NGO Act. The new Act is expected to include provisions that would allow the intelligence service to monitor NGO operations and the President' office to review any request to carry out research in the country. This is one of the latest examples of the ongoing pressures on civil society. The review of the NGO Act comes as there is growing concern among NGOs that the current legal framework is more constraining than enabling for civil society, especially in the context of registration and operations.

\section{Malawi girl guide association (MAGGA)}

The Malawi Girl Guides Association (MAGGA) is the national guiding association in Malawi one of the registered active NGO. It is a member of the World Association of Girl Guides and Girl Scouts (WAGGGS). The Malawi Girl Guides Association membership currently stood at 64, 102 from 3, 375 as of April, 2002. Girl Guide was introduced to Nyasaland during the British colonial era, in 1924 in Zomba then capital. The first training was held in Blantyre, Lilongwe and Mzuzu. Guiding was banned during the reign of President Hastings Kamuzu Banda in 1967 after Malawi attained its 
independence in 1964, replaced by a youth movement called Malawi Youth Pioneers, linked to the Malawi Congress Party, the only political party allowed in what was at the time a one- party state. Girl guiding was re-introduced in 1997 and Malawi Girl Guides was launched on $16^{\text {th }}$ May 2002, after Malawi moved from a one-party state to a multi-party democracy in 1994.

The Malawi Girl Guides Association serves girls aged from 6 to 25 years. Membership includes girls and leaders from all sectors of society. The Malawi Girl Guides Association is active in both urban and rural areas, with units based mainly in schools. Commissioners recruit by giving talks at schools and at church gatherings. MAGGA also works with SAM and the two associations have the objective to help the children develop their full potential in order to become responsible adults and active citizens in the community, through scouting values.

To this aim, both bodies have adopted an educational model that make children responsible for their own personal growth, by giving them opportunities to develop their own knowledge, to be conscious of their rights, and further on to develop professional skills and to acquire a greater independence.

MAGGA and SAM are respectively partners of WAGGGS (World Association of Girl Guides and Girl Scouts) and WOSM (World Organization of Scout Movement), the two international scout networks which together represent 40 million scouts and operate in the whole African continent.

The mission for MAGGA is to help girls and young women develop economically, socially, spiritually and culturally in order to become useful and responsible Citizens of Malawi. The main areas of its activities include development in the fields of Nutrition, communication campaign for change of behavior with respect to SRH/HIV/AIDS, programs of health education, environmental education, programs of leadership training, entertainment skills, gender issues and women empowerment, partnership with the United Nations, other International Organizations and NGOs, fundraising. At world level MAGGA as member of WAGGGS is part of the network of UNAIDS, YWCA (World Young Women's Christian Association) and other UN agencies.

In Malawi MAGGA cooperates with the Ministry of Youth, Sport and Culture and with the National Youth Council of Malawi. MAGGA has also experiences in the field of HIV/AIDS. In 2006 the association implemented a project financed by UNFPA named "SRH/HIV/AIDS Awareness among girl guides".

\section{Activities of MAGGA}

Currently MAGGA is implementing a number of projects throughout Malawi funded by different donors. Some of the projects implemented by MAGGA are listed below:

Strengthening access to sexual and reproductive health services for young people (10-25 years) project

This project is being funded by United Nations Population Fund (UNFPA) and it is being implemented in six districts (Blantyre, Lilongwe, Mzimba/Mzuzu, Mchinji, Karonga and Mangochi). The project is contributing towards achievement of UNFPA's Sixth Country Program, Reproductive Health Component Outcome 1, Output 2

Increased availability of Life Skills education for young people in and out of school" Girl Guiding and Scouting for Sexual and Reproductive Health Promotion

This project is being implemented with funding from Intesa San Paolo (Italian Banks) and Fondazione Cariplo. The project is being implemented in Balaka, Blantyre and Lilongwe in partnership with Scout Association of Malawi.

Promoting positive behavior change in SRH/HIV and AIDS among girls and young women (6-18 years)

This project is being funded by the National AIDS commission of Malawi. The project is currently running in Dowa, Nkhatabay, Rumphi and Thyolo.

Drug and alcohol abuse prevention among in and out of school youth (10-24 years)

This project is funded by Norwegian Campaign for Development and Solidarity (FORUT). The project is currently being implemented in Lilongwe district and is aimed at preventing alcohol and drug abuse among in and out-of-school youth through behavioral change communication interventions. 
Scaling up Children's Corners and psychosocial Care and Support Initiatives for Girl Guides

The project is being technically supported by REPSSI (Regional Psychosocial Support Initiative) which builds capacity for the Association through training of staff and volunteers and mentoring. The project is aimed at ensuring that psychosocial Care and Support (PSS) is mainstreamed in the Girl Guiding Program by establishing Children's Corners. The project is being implemented in Lilongwe, Blantyre and Mzuzu.

Capacity development of Malawi Girl Guides Association

This project is funded by NORAD through the Norwegian Guide and Scout Association and it is aimed at building the capacity of the Association to offer quality Girl Guiding program. This is done through support of operations of the secretariat, training of leaders (Volunteers)at all levels and development of educational programs.

Enhancing Girls' Participation and Completion of Primary School Project

This project is funded by PLAN-Malawi and the goal of the project is to support national efforts to ensure that all children (Boys and Girls)complete a quality primary education by 2015 .

Joint UN Program on Adolescent Girls in Malawi (JPAG)

This project is funded by UNFPA and is aimed at contributing towards accelerating efforts to advance the rights of adolescent girls in Malawi by supporting a range of activities to increase awareness and empower girls to participate in development activities in Malawi. The project is targeting adolescent girls aged 10-19 years in Malawi and it is being implemented in Mangochi and Chikhwawa districts in Traditional Authority (TA) Katuli and sub-Traditional Authority (SubTA)Masache respectively.

This is a new UN foundation led initiative to support UN inter-agency program that empowers adolescent girls (10-19 years). UN agencies in Malawi (UNFPA, UNICEF, WHO, and UNESCO)received funding for a joint UN program for adolescent girls in Malawi (TA katuli in Mangochi and Sub-TA Masache in Chikhwawa). The program takes a holistic approach to addressing the challenges facing adolescent girls. It involves integrated investments in formal education, vocational training, protection from violence, abuse and exploitation of girls.

Stop the violence against girls and young women

The project is implemented by Girl Guides Associations in 25 countries including Malawi Girl Guides Association. It is technically and financially supported by UN Women through World Association of Girl Guides and Girl Scouts. Here in Malawi, Malawi Girl Guides Association implements it in Mangochi and Lilongwe as part of the Girl Guiding Curriculum and it targets Vulnerable Girl Guides in secondary schools by giving educational Scholarships to vulnerable girls. Apart from school fees, the girls were also supported with school uniforms, shoes, sox and other basic necessities like soap and writing materials among others.

AIDSTAR-two/Malawi HIV AIDS civil society capacity building project overview

Project goal: to contribute to the reduction of the spread of HIV/AIDS by providing capacity building technical assistance to local HIV/AIDS organizations to solidify their ability to deliver high impact sustainable services

\section{Other services offered by MAGGA}

Provision of HCT services to young people through the Association' youth center in Blantyre (Limbe). Distribution of female and male condoms to young people through the Association' youth center in Blantyre (Limbe)

Livelihood Skills Training i. e. carpentry and joinery, tinsmith, tailoring through Kapeni Multipurpose Centre in Blantyre (Lunzu)

Psychosocial Care and Support services for orphans and vulnerable children through schools and Children's Corner approach i. e. life skills and resilience building trainings, camps, retreats, congresses etc.

\section{Problem statement}

One of the key challenges in successful financial management in local NGOs is getting finance and program staff to feel that they are working together towards the same goal. Each side needs to 
understand how their roles are both important to achieving the NGO's mission so that they can be bound together as a strong united team. Despite donor' assistance in capacity building to implementing partners, the quality of financial management systems and financial reports are still poor and contributes to low program implementation rate and financial risk. Previous researches have indicated that "poor" or "careless" financial management is a major cause of small business failures (Matoha, 2007).

The outcome of UNFPA for the year ended December 2014 of its annual review workshop, indicated that financial reports that were produced by implementing partners did not meet the time line set by the donor. For example, the donor required that all financial reports for the July September 2014 quarter should have been submitted by 15 October, 2014. However, by $4^{\text {th }}$ December 2014 during annual review meeting, some reports for the $3^{\text {rd }}$ quarter were still not submitted and the implementation rate for some IPs were below $15 \%$. It was not clear whether this situation of low implementation rate was a result of poor quality of financial reports, lack of program monitoring and assurance activities, late donor funding, lack of donor technical assistance, lack of NGO capacity or poor financial management. An NGO with good internal controls, good accounting system, good structure/staffing, proper planning/budgeting, proper accountability/transparency, grant management and proper Financial reporting will likely implement the project activities on time and will have minimal financial risk.

\section{Purpose of the study}

The purpose of this paper is to explore and evaluate MAGGA good financial health management practices which include internal control system, accounting system and the quality of its financial reports submitted to donors in relationship to project implementation rate and how this minimizes financial risk of donor funds.

\section{Objectives of the study}

I. To evaluate the relationship between the NGO financial health management practices and the programs implementation rate.

II. To establish if the Implementation rate of an NGO depends upon effective financial health management practices.

\section{Research questions}

In order to gain a better understanding of the stated problem and to achieve the above objectives, the study was guided by the following research questions:

I. Which are the financial health management practices that contribute to high project implementation rate for small NGOs?

II. What constraints have grass roots NGOs encountered during the implementation of donoraided projects?

To answer the above questions, an analysis was conducted of a case study on good financial health management practices, as well as potential relationship with implementation rate.

\section{Significance of the study}

The study results will bring critical issues concerning financial management of donor aided projects of NGOs and development in general and will probably facilitate a new development perspective towards donor aided projects in Malawi and will be used as a reference in academia and the donor community.

By the time this study was carried out in Malawi, very little study had been carried out on the relationship between good financial health parameters and implementation rate and general challenges that NGOs meet in implementing donor funded projects. It had only been mentioned in broad terms that good financial management with sound internal control systems enhances implementation rate and minimizes financial risk for the donor funds. Emphasis is on good financial practices, compliance to the donor requirements and financial accountability which is critical for grant management and 
project implementation for an NGO. This study was carried to make an academic contribution to this area of knowledge.

The study findings can generate knowledge for the donors about why local NGOs fail to implement programs and comply with its requirements. This can help the donors to identify assurance and capacity building activities and what kind of technical support they should provide the NGOs before giving them any funding in order to ensure that funds will be used for the intended purpose.

The study findings will help NGOs in improving their internal control systems and financial management practices to meet donor requirements and this will improve NGO capability to attract more funding for its sustainability.

The study findings will be a basis for further research on NGO financial health management especially internal control systems required in order to safeguard donor funds.

\section{Scope of the study}

- Geographical Scope

The study covered local NGOs in Malawi supported by donor community and MAGGA in particular which is in central part of Malawi, Lilongwe

- Subject Scope

The study focused on evaluating and establishing the relationship between NGO good financial health management and implementation rate of donor funded programs while minimizing financial risks.

\section{The conceptual framework}

The conceptual framework is developed based on the financial health practices of small NGOs in Malawi supported by donor funds for program implementation with adjustments to fit the current case study. In a study carried by Keating and Frumkin (2003) indicates that financial accountability helps stakeholders such as donors, clients, government and the public assess the financial credibility in the use of funds, which increases public confidence in the governance of the NGOs. In the model for this study, there is relationship between good financial health management practices and program implementation rate. However, for this study, factors such as basic accounting and internal control system, financial reports, staffing, grant management, budgeting and planning are independent variables while implementation rate is dependent variable and is held constant as indicated on figure 1 below 


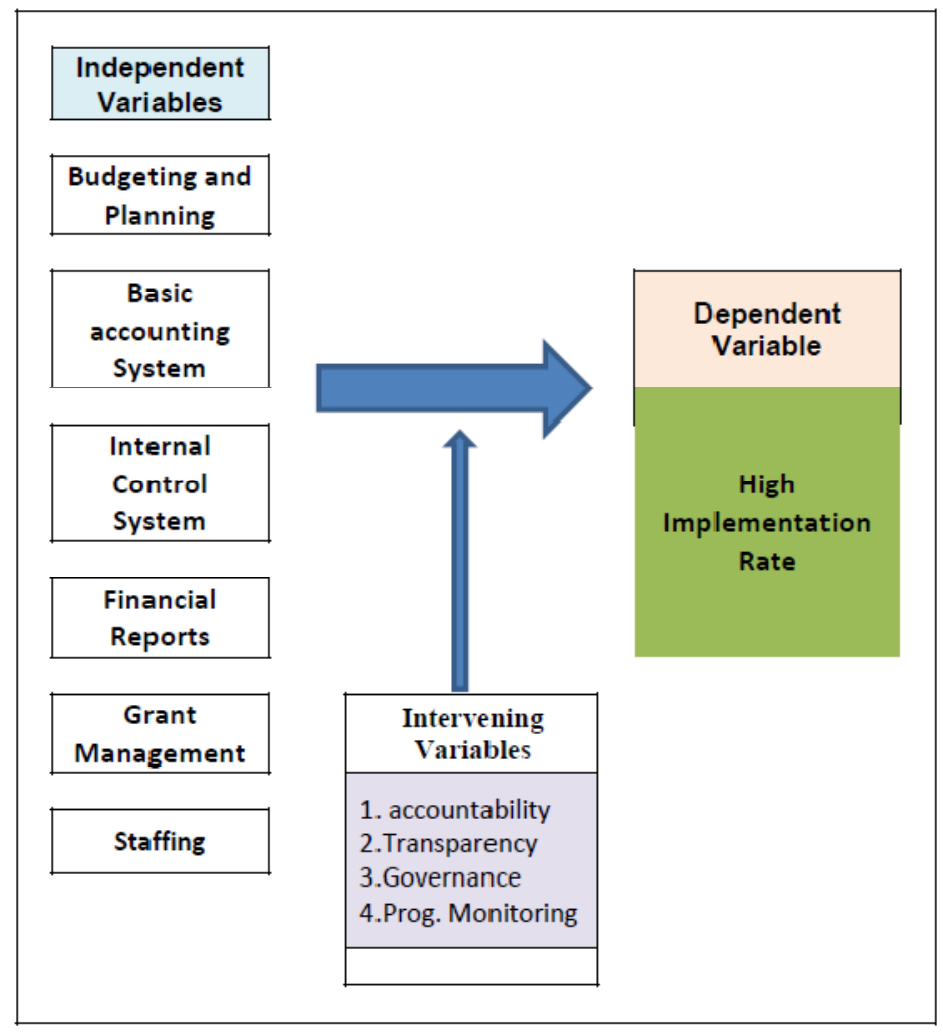

Figure 1. 1: Conceptual Framework of the Relationship between Good Financial Health Practices And Implementation Rate

Source: Researcher's Own Conceptualization

\section{Theoretical background}

There view of textbooks, past research and internet whose contents directly relates to NGOs provides the relevant theoretical background of the thesis project. In addition to textbooks articles that, like the reviewed textbooks, are directly related to NGOs good practices and financial health, financial risk and good governance are scrutinized. The content of the reviewed articles is used to illustrate the theory behind good practices and financial health of an NGO and substantiating it by providing examples of real-life applications.

\section{Empirical Study}

The most suitable solution to answer the research questions is to collect relevant primary data by conducting a survey in the NGOs using donor funds. A questionnaire, a type of survey, containing specific questions that are directly related to NGO good practices and financial health is submitted to staff that are working and implementing programs for the chosen NGO. The questionnaire covers both questions about the good practices and financial health of the chosen NGO.

\section{Case Study}

Because I wanted to look at the NGO good practices, financial health and its effects on implementation rate, I decided to use a research method called the case study. In the case of my thesis, I examined only MAGGA and thus using a single case'.

A case study is a study where the researcher tries to fully understand one or more spatially limited objects or processes. These objects or processes could include an organization or a company. According to Conteh(2001:32), case studies enable researchers to study in-depth peculiarities and idiosyncrasies that may shed light on the prominence of certain, hither toun covered, complex events and processes-most of which may escape statistical manipulations. 
There are several ways a case study can be designed. I will not deal with all these possibilities but I will discuss the techniques used by me. I must make it clear here that there is danger in making any generalization on the basis of what has been discussed on a single NGO case study, although to a very large extent, there are more commonalities than differences for most NGOs, and generalizations are made out of the extensive literature that has been reviewed and my personal experience after working in the international NGOs for the past 15 years.

\section{Literature review}

\section{Introduction}

This chapter provides a critical review of related literature on the relationship between financial health practices and project implementation in small NGOs. Financial health management practice is one of many critical functions in an effective grant management for an NGO. The chapter reviews literature resulting from such studies in Malawi and other parts of the world. The literature is reviewed under the sub sections of accountability and transparency, planning and budgeting, risk assessment, financial and internal control systems, staffing, programme monitoring and grant management as these are regarded as the main pillars for financial health of an NGO in relation to implementation rate of its programs.

Schneider (1985) quoted in Alan Fowler and Rick James(1994); says that, "NGOs play a unique and largely a successful role in assisting and strengthening local groups and associations. NGOs exist to improve the lives of beneficiaries by carrying out activities as described in what NGOs do and finance is a support function to make that possible and the NGO to be more accountable (http://www. mango. org. uk/guide/fmincontext).

Internal control is one of critical area NGOs must promote to achieve their goals. (Harrison et al. 2011, 237. ) observed that internal controls are designed to follow objectives as: safeguard assets, encourage employees to follow company policy, promote operational efficiency, ensure accurate, reliable accounting records and comply with legal requirements. Furthermore, the establishment and the emphasis on good internal control in practice apparently arise because it is considered to be a significant determinant for the organization in order to accomplish its strategic and business goals. (Verschoor 2002). A non-profit organization must adopt strict policy compliance to provide assurances of professionalism, accountability and transparency, and these steps towards legitimacy and stronger ethical practice must "conform to and support 'best practice' guidelines in both its current operations and the firm's future strategic plan" (Bezjian, et al (2009, p. 52).

\section{NGO accountability and transparency}

In review of not-for-profit accountability literature, Brody (2001) defines financial accountability as fiscal honesty and avoidance of fraud. Numerous researches, such as Church and Sneider (1995) and Church (1998 and 2005), examine how the internal control and internal auditing detect irregularities in financial reporting. They conclude that it might be interesting to analyze and examine the impact of internal control and the quality of financial reporting. (Gras-Gil, Marin- Hernandez, 2012).

An NGO operates like a business. It will have bank accounts, own productive assets of all kinds, receive income from sales and other forms of activities including donations, employ staff, enter in to contracts, etc and keeping proper accounting records enables it to prepare reports that give managers important information about how the NGO is doing financially. Langenberg (2004), observed that while NGOs might argue that existing accountability mechanisms are sufficient, voluntarism and selfregulation is not effective. Heargues that simply having a coded does not ensure all organizations will follow the rules. Thus, on the surface, it would appear that some form of mandatory reporting by NGOs forms an ideal measure of accountability.

Marshall (2002), also adds that the most obvious way to ensure that NGOs are transparent is a full disclosure about their activities, which will enhance public trust. The NGO can then make informed decisions so that it can deliver a project within budget, avoid cash flow problems, and make future plans. This can be achieved if they clearly record all its receipts and payments, and file supporting evidence for every transaction; it means that other people can also have a look at what has happened. 
For example, other people within the NGO, donors, auditors and beneficiaries. According to Gale (2003), financial accountability gives NGOs legitimacy and credibility, contributes to their reputation and adds to their sustainability. Good financial accountability limits fraud and mismanagement and attracts donor interests. According to Tilt (2006), the most important issue when considering accountability of NGOs is the means by which they will be required to provide an account. Furthermore, Leat (1988), adds accountability with sanctions, where some form of penalty should be imposed if the account or the actions are inadequate. It is a legal requirement in Malawi for registered entities like NGOs to keep accounting records. If it is not registered as an NGO or a company, it is likely to be a requirement of its head office or donors. Sound administration and finance describes the management of resources, the management of income generation and effective policy that positions the organization as transparent and efficient (León, 2001, p. 17)

Day and Klein (1987), state that fiscal or financial accountability is about making sure that funds have been spent as agreed and according to appropriate rules and regulations. Boice (2004) states that financial accounting is financial responsibility or operational transparency that requires demon starting how donations to your organization have been used and how effective your organization is in achieving its goals. The need for financial accountability has been reflected in a number of studies carried out by different researchers on the subject.

\section{Planning \& budgeting}

According to Financial Management for Non-profit 2001 page 3, planning \& budgeting are those processes where by the organization sets goals and objectives, allocates its resources among its activities and decide show those activities will be operated. Budgeting is a process that relies both on financial information about past performance and the organization's future plans. Budgets should be clear, so that other people can pick them up and understand them easily.

A complete understanding of all costs is critical to good fiscal management, but budgets must be based on accurate information about the organization's programs and services (Kotloff \& Burd, 2012, p. 10). A budget should include historic information, outline trends, identify which assets are restricted and which assets belong to programs. A budget needs to provide are alistic picture of financial objectives. León(2001) suggests that the financial sustainability of an organization relies on strategic and financial planning and sound administration and finance(p. 16). Recognizing that operations can be dynamic, organizations must be clear about financial goals and have a plan which outlines the organization's strategy, priorities, and costs to implement actions (p. 16).

\section{Risk assessment and management}

To identify the key areas of risk to be managed, it is important to assess the probability of an event occurring, the likely level of impact this will have on the business and how the outcome could impact the organization' activities as they align to the overall objectives of the NGO.

According (Terry Lewis, 2013) in his article Mango Management Accounting for Nongovernmental Organizations observed that it is normal to assess an organisation' financial management capacity before funding it. This can help donor judge how much additional funding the NGO can handle. Effective risk management includes risk assessment, risk evaluation, risk treatment, and risk reporting (Collier, Berry \& Burke 2007, 10). According to Collieret al. (2007, 10), risk management has been defined as the process so funder standing and managing the risks that the organization is inevitably subject to in attempting to achieve its corporate objectives (CIMA Official Terminology). The Institute of Risk Management has developed in 2002 a Risk Management Standard, which contains four elements: risk assessment, risk evaluation, risk treatment and risk reporting.

Below is a matrix that can be used to help assess the risks within the organization and prioritize which risks need to be managed 


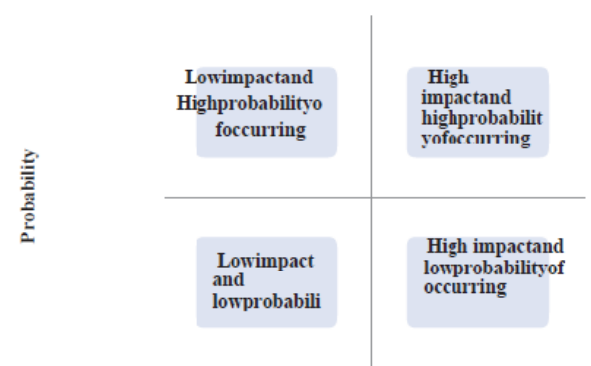

Figure 2. 1: Risk assessment matrix

\section{Impact}

\section{Source: CPA Australia, 2011}

Risk management is viewed as a corner stone of good corporate governance and therefore results in better service delivery, more efficient and effective use of scarce resources and better project management (Collier et al. , 2007). It has to do with identification, analysis and control of such risks that threaten resources, assets, personnel and the earning capacity of a company. In spite of modern business planning models and methods adopted by many organizations, risk assessment is performed non-systematically and intuitively and the risk management plan is not prepared at all (Collieretal. , 2007). Due to this, problems are solved once they arise, usually rather too late.

\section{Program monitoring}

Risk can be minimized by close monitoring of the project activities by both visiting the implementing partner and project site to ensure that the program is actually being implemented. There should be one format form on to ring and reporting throughout the life of the project. This will help to provide a solid basis for analyzing trends and defining strategies, and will be particularly useful when there is a change of personnel, management, and policymakers. Anthony(2004), noted that the purpose of monitoring is to determine whether internal control is adequately designed, properly executed, and effective.

According to the Institute of Internal Auditors (1995) considers monitoring to encompass activities such as periodical evaluations, internal audits and management self-assessments. COSO (1998), Dublin (1990), Magala (2001) and Lary (2009) view monitoring as needed to ensure that planned administrative, operational and financial tasks and activities are carried out in a timely and proper manner such that set internal control objectives and organizational performance are achieved. Monitoring aims at determining whether organizational members are carrying out or have carried out their tasks efficiently an defectively as required by the organization's policies (Spillane, \& Reimer, 2000).

Further, Walker, Shenkir \& Buton (2003) argued that monitoring processes are used to assess the quality of internal control performance overtime. Monitoring is the assessment of internal control performance overtime.

Furthermore, NADC (1996) observed that monitoring is a continuous periodic surveillance of the implementation of a project. Not only should the physical progress of the project be monitored, but also the impact of the project. Changes in external factors which are relevant to the development of the project should also be registered in the progress report. The progress report provides major information input to the project review (NADC, 1996).

According to Dorfman (2007), risk management is the logical development and implementation of a plan to deal with potential losses. It is important for an organization to put in place risk management programs so as to manage its exposure to risks as well as protect its assets. The essence is to prepare ahead of time on how to control and finance losses before they occur.

\section{UN agencies risk assessment}

NGOs funded by some UN agencies in Malawi and elsewhere are assessed for risk and modality for cash transfer and related assurance activities using HACT framework. A Harmonized Approach to 
Cash Transfers to Implementing Partners (HACT) which was launched in April 2005 among the UNDP, UNFPA, WFP and UNICEF. HACT changes the management of cash transfers from a system of rigid controls to a risk management approach aimed at reducing transaction costs, simplifying and harmonizing rules and procedures and strengthening the capacity of implementing partners to effectively manage resources (HACT framework 2014).

There are three key elements for HACT framework all linked to country programming:

The first is assessment of financial management practices to determine risks and identify capacity development needs. There are two assessments on this which include:-

Macro-assessment of the broad public financial management system at the time of the UNCT's efforts to strengthen country analysis, and Micro-assessment of specific implementing partners during the preparation of country programs, leading to the selection of an appropriate cash transfer modality and assurance activities.

The second is assurance activities such as spot check and audits to check that funds are being used for the purposes intended, and to address weaknesses identified by the assessments.

The third is the FACE which is a common format for implementing partners to request funds and report on how they have been used. HACT is intended to serve as a simplified set of procedures on requesting, disbursing, providing assurance, and reporting on funds as a way to effectively manage risks, reduce transaction costs and promote sustainable development in a coordinated manner by carrying micro assessment risk rating.

According to (HACT frame work 2014), the micro assessment questionnaire results in an overall risk rating which comprises one of the following risk ratings:

Low risk: This Indicates a well-developed financial management system and functioning control framework with a low likelihood of potential negative impact on the IP's ability to execute the programme in accordance with the work plan (WP).

Medium risk: This indicates a developed financial management system and control framework with a moderate likelihood of negative impact on the IP's ability to execute the programme in accordance with the work plan;

Significant risk: This indicates an underdeveloped financial management system or control framework with a significant likelihood of negative impact on the IP's ability to execute the programme in accordance with the work plan.

High risk: This indicates an underdeveloped financial management system and control framework with a significant likelihood of negative impact on the IP's ability to execute the programme in accordance with the work plan.

HACT frame work is in line with the observation of (Collier et al. 2007, 10)who defined risk as the process of understanding and managing the risks that the organisation is inevitably subject to in attempting to achieve its corporate objectives. Internal environment sets the tone of an organization, and is the basis for how risk is viewed and addressed by the employees. This includes the philosophy of risk management and risk appetite, integrity and ethical values, and the environment in which they operate. Effective risk management includes risk assessment, risk evaluation, risk treatment, and risk reporting (Collier, Berry \& Burke 2007, 10). The thesis will take a look at the importance of internal control and the different possibilities of how donors are able to minimise the financial risk.

Brody(2001 )and Day and Klein(1987)contend that financial accountability is the fiscal or financial honesty and avoidance of fraud that makes sure that money is spent and recorded as agreed and according to appropriate rules and that accurate reports are given to stakeholders in a timely manner. The big challenge with most NGOs is that they do not have qualified finance personnel and this affect timely preparation of accurate financial reports, which is one of the major donor requirements. Moore (2000) argues that fund development strategies must be suited to the "organization's existing capabilities and have to be fitted to the challenges and opportunities of the environment in which it is operating" (p. 184). Understanding that each donor is different also requires an organization to consider different fund raising methods to determine which options are best and this will assist the NGO to manage the financial risks.

According to ("CPA Australia"), 2011 the central theme of effective internal control is to identify the areas of the organization that need to be monitored and protected, determine where possible risks 
to these areas exist and implement controls to manage these risks. When assessing risk in the organization, a good starting point is to review the overall objectives of the NGO. This is usually documented in the organization's constitution, articles of association, mission statement or strategic plan. Once the objectives have been identified then the next step is to determine the possible risk associated with the achievement of these objectives. This step is critical to NGOs, as it is unlikely all risks can be managed due to the limited resources available.

Joan Hummel states in Starting and Running a Non-profit Organization (1996), "Increasingly, funders, government bodies, and various auditing agents are requiring that the organizations they audit follow program accounting methods" (p. 76). Non-rofit organizations dependent on federal and state governments are required to have financial verification and established accounting procedures to receive monies from such agencies (Grobman, p. 113, 2002).

\section{Internal controls and the accounting system}

Internal controls are systems of policies and procedures that safeguard assets, ensure accurate and reliable financial reporting, promote compliance with laws and regulations and achieve effective and efficient operations. These systems not only relate to accounting and reporting but also include communication processes both internally and externally, staff management and error handling. For each set of policies and procedures it is critical that all relevant staff, volunteers, members and stakeholders are kept informed. Effective communication can be executed in many different ways, such as through the intranet, employee and volunteer handbook/induction pack, newsletters and bulletins, regular meetings and memos.

Internal controls help NGOs handle everyday risks of mistakes, confusion or fraud. They also protect staff from any pressure to mis-use funds and from the suspicion of wrong-doing. According to("CPA Australia"), 2011 Effective internal controls require planning and assessment by the organization from the outset. This is particularly true for NFPOs as personnel and financial resources are often limited. Where this occurs, it is essential for internal controls to be established within the limits of the organization to ensure they are effective and can be supported by the available resources. Internal control is effective if management and interested stakeholders have reasonable assurance that they understand the extent to which operational objectives are achieved, . published financial statements are being prepared reliably, applicable laws and regulations are being compiled.

The control environment is created and enhanced by setting policies and procedures that embrace the overall objectives of the organization. Such policies and procedures should cover the human resources- including hiring policies, conflict of interest, job descriptions, training, performance evaluations, remuneration and disciplinary procedures. NGOs leadership should establish internal control systems that will ensure a code of ethical conduct and a frame work for internal regulations, including systems and by laws which will ensure that management is accountable for the financial and other resources within the boundaries set by the rules of the donor.

Administration and financial-including job responsibilities, segregation of duties, procedures for key administration activities, reporting relationships, financial authorities and access to assets reporting-including frequency, content, preparation responsibility, identification of stakeholders

Systems-including access security, system hardware and software purchase and maintenance, procedures for key activities such as purchasing and disbursement of funds, disaster recovery and emergency planning. In order to achieve consistent financial accountability it is necessary to establish standards and a system for accounting practices.

According to Keating \& Frumkin (2003), in most NGOs funds from donors are poorly managed and their accounting systems are in poor order. This statement confirms the findings of many researchers on the importance of accounting system and internal controls in an NGO for it to win the donor confidence. Collins and Collins (1978), contend that an accounting system is a way of keeping a written record of transactions. Furthermore, Larson \& Pyle (1988) noted that accounting system consists of business papers, records, reports and procedures that are used by an organization in recording transactions and reporting their effects. Welsch and Short (1987) added that an accounting system, regardless of the size of the organization is designed to collect, process and report periodic financial information about the entity. 
According to Doornbos (2003) one area that typically comes up for special mention in donorrecipient relationships is that of financial accountability and it stands out as the heart of good governance concerns. Schnelder (1989) stresses that the heart of fiscal management in any organization is a good accounting system, that is appropriate to that organization. Ebrahim, (2003) notes that NGOs respond to issues of accountability with both tools and processes. An NGO should put in place tools like financial accounts, monitoring, quarterly reports, annual reports, performance assessments, independent evaluations and audits.

This means that once internal controls have been established for the key activities of the organization, the effectiveness of these controls requires monitoring to ensure that the objectives of the controls are being met. Ongoing monitoring activities include management and supervisory activities that evaluate and improve the design, execution and effectiveness of internal controls. Other ways that internal controls can be monitored is through the use of internal audits, self-assessment by employees, volunteers and managers, periodic review by an audit committee and spot checks to the internal control activity as observed above by Ebrahim, (2003).

\section{Financial reporting}

Donors usually like to have reports in a specific format and by a specified time. It is normal for there to be both narrative and financial reports, and it is important that they match and complement each other. It is really important to try to meet donor reporting conditions as late or wrong reports reduce a donor's confidence in your organisation. The key to easy reporting at the end of a period is setting up systems properly at the beginning!. According to Gale (2003), poor quality of financial reports greatly diminishes the quality of NGOs and he further noted that integrity of the non-profit sector is served best if NGOs are accountable (Gale, 2003).

Furthermore (Sioan, 2001) observed that the financial report is the first source of independent and true communication about performance of company managers. Cohen, Krisnamoorthy and Wright, 2004 added that one of the most important functions of corporate governance is to ensure the quality of financial reports. Keating and Frumkin (2003), state that in order to determine the effectiveness of a financial reporting system, one must understand its objectives. According to Eyong (2001), good governance means the effective management of an NGO's resources in a manner that is open, transparent, accountable, equitable and responsive to people' needs.

Keating and Frumkin (2003) argue that the not-for-profit community's future economic success depends not only on the quality of its social economic activities, but also on improving its internal accounting and external financial reporting systems. Hughes (2003) agrees with this argument by stating that it is governance, through organizational capacity, not accountability that challenges notfor-profit organizations most. To supplement this argument Light (2002), said that improving governance through developing organizational capacity should be the first step, for without it even plans cannot be implemented. Regular financial reports play a crucial role. This might include audited annual financial statements or regular budget monitoring reports (which compare actual expenditure to budget). They might be required every three or six months. An external audit can provide assurance that financial statements are true and fair. Financial reports have to be read alongside narrative reports, so that you can build up a picture of what has been achieved with funds and whether it seems to represent good value for money (Terry Lewis, 2013)

\section{Grant management}

The key to making funding relationships work is open and regular two way communication. In particular, in depth discussions before any agreements are signed will save problems during the implementation stage. Effective communication builds mutual trust, respect, and commitment to keep promises - all critical in funding relationships.

Most NGOs are dependent on donor funds (and donors are dependent on implementing partners!). Proper grant management and keeping donors happy is key to achieving objectives, and financial survival for an NGO. According to Terry Lewis, 2013 restricted funds can only be used for specific purposes that have been agreed with the donor. The restrictions may be very tight (e.g. to pay for a new photocopier) or rather general (e.g. to help fight HIV/AIDS). Project-based funding from external 
donors is nearly always restricted. It is useful because it provides money for an NGO to pursue its objectives. Terry Lewis, 2013 further observed that donors can also bring problems to NGOs which includes:

- Big investment in writing proposals and developing relationships with donors and writing reports.

- It is unpredictable - you may win a grant, or you may not.

- It tends to be tied to donors' priorities - not your NGOs' priorities. It can create dependency. What will you do when the grant ends?

- It often comes with specific conditions attached to how you spend it.

- Specific project plans can make it hard to adapt to changing local circumstances, or meet unforeseen costs.

NGOs often receive funds from donors, which they spend themselves and sometimes pass on to other organisations. For example, it is common for a government department to fund an international NGO which funds a local NGO which funds grass-roots community organisations. Donors and NGOs need each other. Donors provide funds, and without funds NGOs cannot achieve their objectives. But donors also have their own agendas and objectives which they cannot achieve without implementing NGOs (Terry Lewis, 2013)

Developing good relationships and shared understanding is really important if both sides are to work together effectively to achieve their goals. But managing relationships between organisations is not easy - you will probably have experienced challenges like language and culture differences, lack of understanding or respect for each other, problems with email communication, funds sent late, accountability reports sent late, difficult grant conditions and the messy complexity of implementing aid or development programmes. All this makes for a challenging environment (Terry Lewis, 2013)

Donors have a great deal of power and influence in the NGO sector. Donors face a difficult job. They have to use their funds responsibly, to achieve their goals and avoid fraud. This means making sure that basic controls are in place. But they also aim to support effective local responses and help organisations grow. This means encouraging flexibility and learning.

Having the money puts donors in a powerful position compared to the organisations they funddonors are very influential. If they get the balance between control and flexibility very wrong in either direction, it can be damaging to the NGO. This means that donors have a serious responsibility to the organisations they fund.

\section{NGO structure/staffing}

According to (CPA Australia 2011) assets an effective control environment is an environment where competent people understand their responsibilities, the limits to their authority, and are knowledgeable, mindful and committed to doing what is right, and doing it the right way. These people are committed to the organization's culture and follow the policies and procedures that are in place to support that culture. It further argued that the success of the control environment will rely on the board and management creating a positive "to neat the top" and demonstrating their commitment to internal controls by adhering to the organisation's policies and procedures. Furthermore (Kotloff \& Burd, 2012, p. 10) observed that having appropriate software and trained staff helps to reduce inefficiencies and generate more accurate and reliable financial information.

According to Chartered Institute of Public Finance and Accountancy (CIPFA, 2013) a good performance management system will help employees understand how their roles and responsibility relate to the achievement of the organization's goals. It further argued that, by setting individual targets that stem directly from those of the organization staff should be motivated to work for the good of the organization.

NGOs will need to mature, through increasing professionalization of staff, methods and financing (Cohen, 2003). Harris (1996) states that legally for most NGOs the Board is supposed to govern those NGOs but in practice, the governance may be exercised by a range of stakeholders- board, staff, clients, funders, founders and other key stakeholders like government. To manage an NGO requires good leadership qualities to spearhead the achievement of the organizational goals. Ideal leadership qualities include a desire to make a difference, blended with skills and knowledge, and the 
opportunity to act which is absent in most NGOs management team. Miller and Bergman (2008) suggest that "good board leadership exhibits passion, commitment and vision.

According to (Fowler 2000, Hope 2002) noted that there has been a push towards decentralization and NGO shave adopted different solutions such as delegation to solve their problems. Leadership needs to ensure that reporting resources, technology, software, Orin-house skill, is a match for the programs and services at the core of its mission or mandate. Having skilled staff will help the NGO to produce high quality financial reports and limiting this capacity as the case with many small NGOs also limits oversight functionality of the organization and affect program implementation rate. According to John L. Colley, JR., Jacqueline L. Doyle, George W. Logan, \& Wallace Stettinius (2003). Observed that directors need to follow the laws and build records of what they have done to protect themselves from challenges that have the advantages of hindsight. He further argued that the elected directors assumes the obligation to represent the interests of fiduciary responsibility and also that directors who are dump but honest fail to fulfill their obligations.

At times NGOs fail to implement programs because of lack of capacity as they receive funding from different donors on the expense of few staff at the same time being accountable to so many donors.

According to Leat, (1988), the issue of multiple stakeholders, while at best making accountability more complex, can additionally be problematic for NGOs because such competing demands can actually lead to poor performance. Over the recent past years there has been a lot of concern about poor programs implementation rate in NGOs leading most NGOs returning funds to the donor at the end of financial year because of failure to utilize the funds. This has been reflected in a number of studies carried out by researchers on the subject in Malawi and elsewhere.

Review of the literature show overwhelming support that implementation rate of NGO programs depends on effectiveness of financial health practices. This means that for NGOs to achieve high implementation rate, they are supposed to strengthen all the six financial health parameters.

\section{Research methodology}

Introduction This chapter describes the methodology that was employed in conducting the study. It specifies there search design, the study population or the area in which the study was conducted, the sampling design, the sample size, data sources, data collection instruments and the validity and reliability of the data collection instruments. It further describes the data analysis method, ethical considerations and the limitation of the study.

\section{Research design}

A written survey questionnaire was developed to evaluate the NGO financial health status which covered planning and budgeting, basic accounting system, financial reporting, internal controls, grant management and general questions regarding NGO good practices.

This study aims to evaluate MAGGA by collecting and analysing empirical data relating to its good practices and financial health and also investigating MAGGA characteristics that affect either the implementation rate or the techniques used to avoid financial risks. The results help provide a more comprehensive picture of current NGOs good practices and financial health and the factors that influence program implementation rate.

\section{Study population}

The study specifically investigated MAGGA an NGO based in Lilongwe with funding from different donors and covered its operations in almost all regions of Malawi.

\section{Sampling design}

Stratified random sampling design was used for this study. 21 staff from different departments was asked to complete the questionnaire. 3 were from the finance department 8 from operations, 2 were from top management. 3 program officers were also involved including 5 officers from other districts offices of Blantyre and Mzuzu. The sample was based on the proportionate number of staff in each department in relation to the total number of staff. 


\section{Sample size}

In this study a sample size of 21 respondents was taken to represent the population of 30 staff. Respondents were selected to represent the different staff levels of MAGGA. The selection of the respondents was made randomly based on availability and willingness to respond and complete the questionnaire of the researcher.

Table 3. 1: Level of Respondents

\begin{tabular}{|l|c|}
\hline Department & Total Respondents \\
\hline Management & 2 \\
\hline Finance department & 3 \\
\hline Other Districts & 5 \\
\hline Program officers & 3 \\
\hline Operations & 8 \\
\hline Total & 21 \\
\hline Source: Primary data \\
\hline
\end{tabular}

\section{Data sources}

\section{Documentary review}

This researcher also reviewed literature obtained from the case study NGO. This literature included project documents, project and annual reports, project review reports and research reports that had been conducted by the case study NGO on the projects that they implement. This method was chosen because; it was vital in providing background information and facts about project simple mented by the case study NGO before primary data could be collected.

Annual audit and financial reports, internet, interviews and questionnaires were used because of their relevance to the research. A qualitative approach with the emphasis on case study method of research was used for evaluating good practices and financial health of NGOs and the research basically focused on the descriptive and explanatory case. Questionnaire designed to answer their search questions of the study and interviews were conducted with the respondent' staff and managers of the NGO.

\section{Data collection instruments}

There search instruments used included Mango's Financial Health Check structured questionnaires with pre-coded answers administered to the respondents. The instruments were pre-tested and discussed with the supervisors.

Mango's Financial Health Check helps assess the health of organization's financial management. It is designed as a self-assessment tool so that you can identify the areas where you need to improve. The Health Check is a set of statements of good practice. They cover all the key areas of NGO financial management. For each statement, you consider how well the organization is in line with good practice

\section{Reliability of the instruments}

Mangoisa UK based charity which exists to strengthen the financial management of not-for-profit organizations, including NGOs. Mango publishes freely available tools, like this one, as well as running training courses and providing finance staff to work with NGOs. The tool was particularly designed for small and medium sized not-for-profit organizations (or field offices). This includes NonGovernmental Organizations, schools, medical centers, churches etc.

\section{Measurement of variables}

Six key variables were measured using scores 5, 4, 1 and 0 . These included planning and budgeting, basic accounting system, financial reporting, internal controls, grant management, staffing and general questions regarding NGO good practices. 
Respondents' answers ranging from True, sometime and not true was used to collect information which was used to measure variables. The measurement of the variables was done against the general accepted accounting standards GAAT.

\section{Data analysis}

The primary data that is used in the analysis is the result of the survey conducted at MAGGA where all the data collected was coded and arranged according to the research themes to exam the real life situation. Due to the number of questions raised in the questionnaire and the comprehensiveness of the survey, a quantitative method will have to be used along-side descriptive and explanatory analyses, where appropriate. To some extent, quantitative elements like percentages, ratios and graphs will be used to give more meaning to data analysis and interpretation which will provide the best possible outcome when analyzing and interpreting the primary data. This gave the researcher an opportunity to get a deeper understanding of NGO good practices and financial health practices. For this reason I have used Mango financial health tools to say something meaningful about the quantitative data.

\section{Ethical considerations}

This research took into consideration a number of ethical considerations namely here;

- Permission was asked and obtained from relevant NGO before the researcher was allowed to conduct interviews with staff from the respective NGOs.

- Secondly, all secondary materials in this research, their sources have been provided and Quotes from individuals respondents, their names have been concealed for confidential reasons.

\section{Limitations of the study}

Although this study was conducted in the most professional manner possible, the deadlines for this project allotted a limited amount of time for data collection. Additionally, some staff refused to respond to complete the questionnaire or give out information of the NGO due to the sensitive subject matter. This severely limited the responses collected. The researcher endeavoured to capture some statistical data both from the primary and secondary source and these have been used to bridge this gap. Despite these limitations sufficient and reliable data was collected to render the study meaningful in order to arrive at a useful conclusion.

\section{Data presentation and interpretation}

\section{Introduction}

This chapter presents the key findings of this research according to research objectives and the research questions. The findings in this chapter have been arranged according to the following research themes, evaluation of the existence of good financial health practices in small NGO which include accounting and internal control system, financial reporting, planning and budgeting, grant management, and staffing where it will offer descriptive analysis followed by analysis by research objectives. The chapter further looks into the constraints grass roots NGOs like MAGGA encountered during the implementation of donor-aided projects. The results are categorized per different analysis test performed

\section{Descriptive analysis}

To analyse data emerged during the interview and review of NGO audit reports, donor spot check and monitoring reports and general responses which were not covered by the questionnaire, a descriptive analysis is compiled in line with the research variables. These describe the respondents in terms of responses to financial health practices of the chosen NGO which include planning and budgeting, internal controls, staffing grant management and financial reports discussed below:

\section{Descriptive analysis -planning \& budgeting}

For good financial management, an NGO need to prepare accurate budgets, in order to know how much money is needed to carry out NGO work. A budget is only useful if it is worked out by 
carefully forecasting how much you expect to spend on your activities. Budgets should not be documents, which are developed each year, only to be filed away until the next year. They should be useful tools, used to anticipate problems and to provide a baseline against which actual program and financial experience can be monitored.

When budgets are designed to create an impression rather than an expression of program plans, they lose their ability to assist the organization in planning, monitoring and controlling.

The research has revealed that MAGGA has effective budgets which accurately anticipate and project the inter play between program and fiscal activity though we noted that budgets are not prepared in good time for all costs for running the NGO. An effective budget serves as a guideline, which reflects the best estimate by an organization's decision makers of the anticipated income and the costs of operating various program activities.

Budgeting is about working out how much your planned activities are likely to cost. The research has revealed that both program and finance staff is involved in setting budgets, which has assisted MAGGA to create a foundation for good cooperation and coordination during implementation and budget monitoring. MAGGA makes a 12 month cash flow forecast January to December which is as important as a budget. MAGGA implements and reports on quarterly basis and this help them to prioritize the timing and scale of planned activities and to spot cash flow problems in goodtime.

Budget shave a crucial role to play in strong financial management. MAGGA board approves budgets and they check if it is aligned and reflect the planned strategic direction of the NGO. MAGGA project manager during the interview noted that budget assist them to guide implementation and check on progress. The research also revealed that MAGGA is currently not using computer accounting package which also poses a challenge for the NGO to use the accounting codes for budgeting. The absence of the accounting codes makes the finance and program team difficult to track actual spending against expected expenditure in the budget monitoring reports.

\section{Descriptive analysis - basic accounting systems}

A basic accounting system is in place and working using excels sheets. The acting Executive director of MAGA during the interview revealed that they used to have computerized accounting package which is currently not working as it was destroyed by thunder storm. Despite this weakness we noted that most financial transaction are backed up by a 'supporting document', e. g. a receipt, invoice or sign sheet (e.g. for many travel reimbursements) as revealed in 2013 UNFPA quarterly spots checks reports and annual audit reports which was made available to the interviewer.

MAGGA check the accuracy of the accounting books at the end of each month by carrying out reconciliations'. The bank statement balance is compared to the bank cash book closing balance. A physical cash count is done to check the closing balance in the petty cash book.

The research has further revealed that MAGGA is currently not using the accounting codes instead they are using the donor descriptive activity lines to guide them on project implementation and budget monitoring.

\section{Descriptive analysis - financial reporting}

This section reports on the findings on preparing, reviewing and submitting financial reports to the donor. A normal financial report summarizes income and expenditure over a certain period of time which is created by adding together similar transactions. Financial reports summarize the information held in the cash book. This is normally done using a system of codes, to allocate transactions to different categories. Reports should also have the right format for their use, e.g. donor formats as per grant agreements, standard formats for annual audited accounts, accessible formats for beneficiaries, user friendly formats form an agers

The research revealed that MAGGA prepares reports for its donors on quarterly basis though Board of Trustees does not review it on quarterly basis as required to oversee the finances of the NGO. Managers need up-to-date figures to monitor projects and make decisions. Donor agencies need reports to check the use of their money, and often as a condition for further funding. Increasingly, organizations are sharing financial information with beneficiaries to increase accountability and build confidence. The research further noted that MAGGA has annual external auditors who verify the 
accuracy of the financial statements apart from donor quarterly monitoring visits and spot checks. Project managers should use financial reports to help make decisions so that the money is used efficiently and effectively to achieve desired outcomes.

The research has further revealed that MAGGA submit reports to its donors based on the donor requirement as different donors requires different reporting formats showing the relevant level of detail according to grant agreement or letter of understanding (LOU )for example, UNFPA and other $\mathrm{UN}$ agencies have a standard format for NGO requesting funds and reporting using what they call Funding and Authorization Certification of Expenditure (FACE) form

\section{Descriptive analysis- Internal Controls}

The central theme of effective internal control is to identify the areas of the organization that need to be monitored and protected, determine where possible risks to these are a sexist and implement controls to manage these risks.

This section specifically investigated and presents results on Internal control activities used by MAGGA which include approvals, authorizations, verifications, reconciliations, reviews of performance, security of assets, segregation of duties, and controls over information systems. Essentially control activities will assist in deterring, preventing and disclosing risk events in the organization.

The checklist which was used through a questionnaire revealed that Internal controls systems of policies and procedures that safeguard assets, ensure accurate and reliable financial reporting, promote compliance with laws and regulations and achieve effective and efficient operations are in place and working. These systems not only relate to accounting and reporting but also include communication processes both internally and externally, staff management and error handling.

Sound internal controls which is in place and working at MAGGA include procedures for handling funds received from donors and expended by the organization, preparing appropriate and timely financial reporting to donors, board members and senior management, conducting the annual audit of the NGO's financial statements, evaluating the performance of the NGO, evaluating staff and programs, maintaining inventory records of property, implementing personnel and conflicts of interest policies.

The above controls have assisted MAGGA to safeguard the assets; accounting records are accurate and up to date, timely submission of reports to donors and this has contributed to record high implementation rate of its programs.

\section{Descriptive analysis - grant management}

MAGGA get its funding as grants from donor partners. The interviews revealed that it has grant agreements in place that outlines the amounts and timings of funds to be transferred. Its donors fund specific projects with specific budgets which form part of the agreement.

The finding of this research builds on the practical realities of grant management. The research noted that grant agreement contains a number of grant conditions, including procurement rules and reporting requirements. Furthermore, we noted that program and finance staff work together to ensure consistency between the narrative and financial reports about the same project.

MAGGA work with five donors since 2010 and there is a signed grant agreement in place for each grant. The research further revealed that donors receive financial reports in the right format and on time. The research revealed that MAGGA keep track of which donor is funding which project (or part of a project) and it avoids borrowing money received from a donor for a specific project for another purpose.

\section{Descriptive analysis - Staffing}

This section investigated on the skill possessed by the board, managers and program officers and finance team to effectively contribute to the achievement of the NGO goals. The role of the board is not to undertake operational activities, but to support and govern- the exception to this is in the case of small NGO like MAGGA. An important part of the board's responsibility is to question and monitor the activities of the organization, especially in relation to the financial health and overall 
viability of the NGO. It is imperative that the board develops appropriate methods to undertake this responsibility, such as reporting mechanisms and board sub committees (e. g. Audit risk committee) that provide an appropriate over view of relevant information.

MAGGA acknowledged during the interview that it is under staffed as the Executive director is not yet recruited and there is one in acting capacity with the skills need to oversee all the financial activities and, at times, there is a need for everyone in the NGO to contribute to particular tasks to get a job done. From a governance perspective, this often means that MAGGA acting Executive director move from an over sight role into an operational role. However, the research noted that all roles have clear definitions and boundaries which remain clear, even if the same person is fulfilling a range of duties.

Good financial management is dependent on staff with the right skills, support, and attitude to carry out the irresponsibility's. All staff has a role to play in financial management. The accounting staff is part of a wider team including the Executive Director, Program Managers and the Board. The scoring of the questionnaire revealed that MAGGA has staff with required qualification and skills and work as a team in achieving the NGO objectives which has resulted achieving over $83 \%$ implementation rate since 2010 to 2013 as seen in figure 11. Integrating good financial management in to programs involves budget holders and finance staff working hand in hand through all the stages of the financial cycle.

It may be difficult to assess the technical competence of accounting staff. Good indicators are the timeliness of reports, then neatness of files and records in the accounts office, and auditor's comments or recommendations. Review of financial and program reports submitted to donors and the analysis of the data revealed that MAGGA submits reports to its donors on time which has assisted the NGO to improve its relationship with donors.

\section{Analysis of the results based on independent variables}

To achieve the objectives of the research, each statement of best financial health management practices was discussed whether it is true, or is in place, or happens through questionnaire administered for each section. It was agreed on a score based on what actually happens, not what is supposed to happen, or what is documented in finance manual of MAGGA. The scores used were 5, 4,1 and 0 only.

Table 4. 1: Explanation of Scores used

\begin{tabular}{|l|l|}
\hline Explanation & Score \\
\hline Our practice is totally in accordance with the statement & 5 \\
\hline Close to 5, but not quite there & 4 \\
\hline Close to 0, but not that poor & 1 \\
\hline This is not in place, or is not true or does not happen & 0 \\
\hline
\end{tabular}

After collecting and cleaning the data it was summarized for analysis. Packages Scientists (SPSS)was not used due to nature of the data including statistical tests were not run to analyse the data.

\section{Interpreting the Score}

The purpose of this study was to analyse the relationship between financial health management practices and the implementation rate. To determine the effect of financial health management practices on implementation rate, a questionnaire was administered and findings are summarised below.

Score for each section was summarised in table 4.1 below and then compared it to the columns on the right table 4. 2. 1 which show the appropriate level of financial health management practices assessment for each section the research evaluated.

Table 4. 2: Summary of Results (Scores)

\begin{tabular}{|l|l|} 
Financial Health Practices & MAGGA Score \\
\hline
\end{tabular}




\begin{tabular}{|l|c|}
\hline 1. Planning and budgeting & 34 \\
\hline 2. Basic Accounting Systems & 51 \\
\hline 3. Financial reporting & 29 \\
\hline 4. Internal controls & 73 \\
\hline 5. Grant management & 35 \\
\hline 6. Staffing & 32 \\
\hline Total Score & 254 \\
\hline
\end{tabular}

Table 4. 2. 1: Level of Risk/Good practices

\begin{tabular}{|c|c|c|}
\hline $\begin{array}{c}\text { Low Financial } \\
\text { Integration }\end{array}$ & $\begin{array}{c}\text { Medium Financial } \\
\text { Integration }\end{array}$ & $\begin{array}{c}\text { High Financial } \\
\text { Integration }\end{array}$ \\
\hline $0-25$ & $26-40$ & $41-50$ \\
\hline $0-30$ & $31-50$ & $51-60$ \\
\hline $0-20$ & $21-35$ & $36-40$ \\
\hline $0-40$ & $41-60$ & $61-75$ \\
\hline $0-15$ & $16-25$ & $26-35$ \\
\hline $0-20$ & $21-30$ & $31-40$ \\
\hline $0-150$ & $151-240$ & $241-300$ \\
\hline
\end{tabular}

Source: Primary data

The analysis of the results in figure 5 above indicates that the NGO scored 254 overall which is $84 \%$ financial health management practices integration. Score range from 241 - 300 shows high financial integration. This means that there is high financial integration for this NGO. The financial management of the NGO is in good shape. The risks of the NGO not being able to complete its programs because of financial problems are low.

An NGO effective financial management requires strength in all six areas in the above figure. We have considered each section and analyzed below:

\section{Planning and budgeting}

According to Financial Management for Non-profit 2001 page 3, Planning \& budgeting are those processes where by the organization sets goals and objectives, allocates its resources among its activities and decides how those activities will be operated. On planning and budgeting the results shows that the NGO scored 34. The NGO has a reasonable level of integration of financial management. The NGO can improve the situation with some careful planning. Further improvements may be very useful, helping prevent misunderstandings and conflict; making procedures more efficient; helping staff do their jobs better and more efficiently; and making more effective use of the donor funds.

\section{Basic accounting systems}

According to Keating \& Frumkin (2003), in most NGOs funds from donors are poorly managed and their accounting systems are in poor order. Contrary to this statement, the results show that the NGO has basic accounting system in place and scored 51 on this section. This means that the NGO has a high level of integration of financial health management practices in this area which is in conformity with Schnelder(1989)who stresses that the heart of fiscal management in any organization is a good accounting system that is appropriate to that organization. Ebrahim, (2003) notes that NGOs respond to issues of accountability with both tools and processes. An NGO should put in place tools like financial accounts, monitoring, quarterly reports, annual reports, performance assessments, independent evaluations and audits. Marshall (2002), also adds that the most obvious way to ensure that NGOs are transparent is a full disclosure about their activities, which will enhance public trust. The NGO can then make informed decisions so that it can deliver a project within budget, avoid cash flow problems, and make future plans. This can be achieved if they clearly record all its receipts and payments, and file supporting evidence for every transaction; it means that other people can also have a look at what has happened if good accounting system is in place. 


\section{Financial reporting}

The NGO scored 29 and this shows that the NGO has a medium level of integration of financial management practices in this section. The results is in line with the observation of (Sioan, 2001) who argued that the financial report is the first source of independent and true communication about performance of company managers. Cohen, Krisnamoorthy and Wright, 2004 added that one of the most important functions of corporate governance is to ensure the quality of financial reports.

Furthermore Gale (2003), observed that poor quality of financial reports greatly diminishes the quality of NGOs and he further noted that integrity of the non-profit sector is served best if NGOs are accountable (Gale, 2003).

Keating and Frumkin (2003), state that in order to determine the effectiveness of a financial reporting system, one must understand its objectives. Poor results in this section could lead to misunderstandings and conflict with donors on financial accountability. (Terry Lewis, 2013) assets that financial reports have to be read alongside narrative reports, so that you can build up a picture of what has been achieved with funds and whether it seems to represent good value for money.

\section{Internal controls}

According to ("CPA Australia"), 2011 Effective internal controls require planning and assessment by the organization from the outset. To agree with this statement the figures show that the NGO scored 73 in this section which was the highest score compared to other sections. According to (HACT frame work 2014), such type of results indicates a developed financial management system and control framework with a moderate likelihood of negative impact on the implementing partner's ability to execute the programme in accordance with the work plan. This will help the NGOs handle everyday risks of mistakes, confusion or fraud and protect staff from any pressure to mis-use funds and from the suspicion of wrong-doing. Furthermore, the NGO will minimize financial risk and use the organization resources effectively. This statement is supported by (Collier et al. , 2007). Who observed that risk management is viewed as a corner stone of good corporate governance and therefore results in better service delivery, more efficient and effective use of scarce resources and better project management.

\section{Grant management}

The analysis in figure 5 shows that the NGO in this section scored 35 which show that there is a high financial health management practice. Proper grant management and keeping donors happy is a key to achieving objectives, and financial survival for an NGO. The result in this section undoubtedly contributed to win donor support and high implementation rate

\section{Staffing}

According to (CPA Australia 2011) assets an effective control environment is an environment where competent people understand their responsibilities, the limits to their authority, and are knowledgeable, mindful and committed to doing what is right, and doing it the right way. This statement is confirmed by the results of the case NGO who scored 32. A range of $31-40$ is regarded as high financial health practices in this section. The results show that the NGO has competent staff that can assist the NGO to achieve its intended goals. The researcher also observed elements of good leadership and governance. This is in line with the observation of John L. Colley, Jr. , Jacqueline L. Doyle, George W. Logan, \& Wallace Stettinius ( 2003)who noted that directors need to follow the laws and build records of what they have done to protect themselves from challenges that have the advantages of hindsight. 


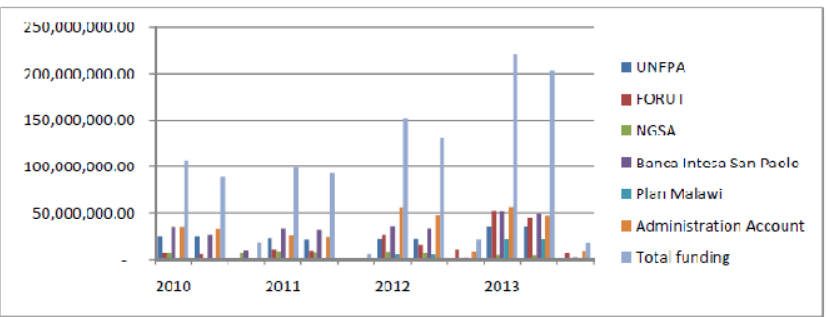

Figure 4. 1: NGO donors and funding levels

Source: Primary data

The figure above shows that the NGO had five donors and administration account. Its total funding in 2010 to 2013 ranges from 107 to 221 million Malawi Kwacha. This shows that the NGO has won the interest of donors. The steady funding for four consecutive years by the same donors shows that the donors have confidence in the NGO and there is low level of financial risk. The good score of the six variables by the NGO in figure 4. 2 contributes to attract the donors. The observation in figure 4.1 above is in line with a study carried by Keating and Frumkin (2003) which indicates that financial accountability helps stakeholders such as donors, clients, government and the public assess the financial credibility in the use of funds, which increases public confidence in the governance of the NGOs.

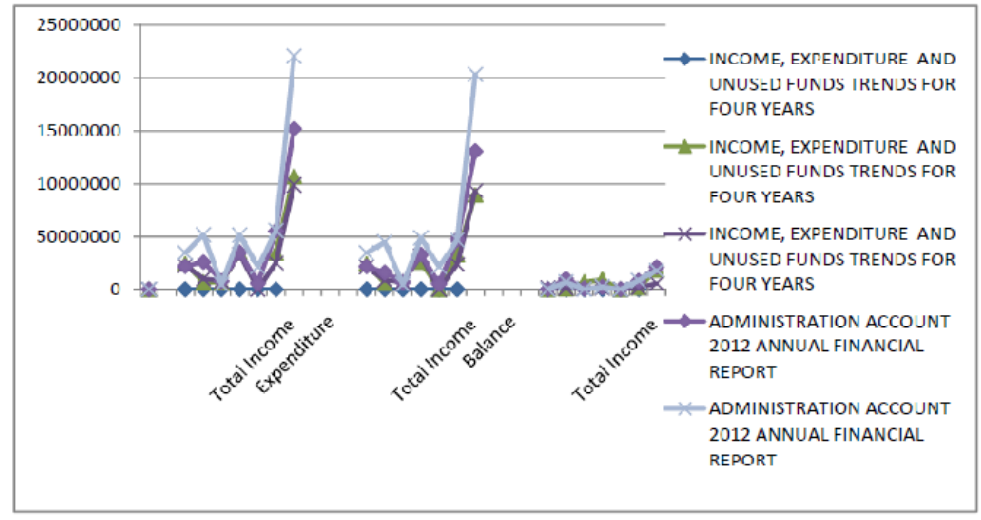

Figure 4. 2: Funding and Liquidation Trends 2010 to 2013

Source: Primary data

The results above reveal that since 2010 to 2013 MAGGA had a steady funding and it appears that the NGO implemented its programs on time as revealed by the trend above. The figures show that the monies from the donors increased quite significantly infavour of the case NGO, however at an increasing rate for internally generated funds in administration account. There was high percentage of funds used compared to the remaining unutilized funds at the end of each financial year. The trend also confirms that the NGO has capacity to implement the activities. 


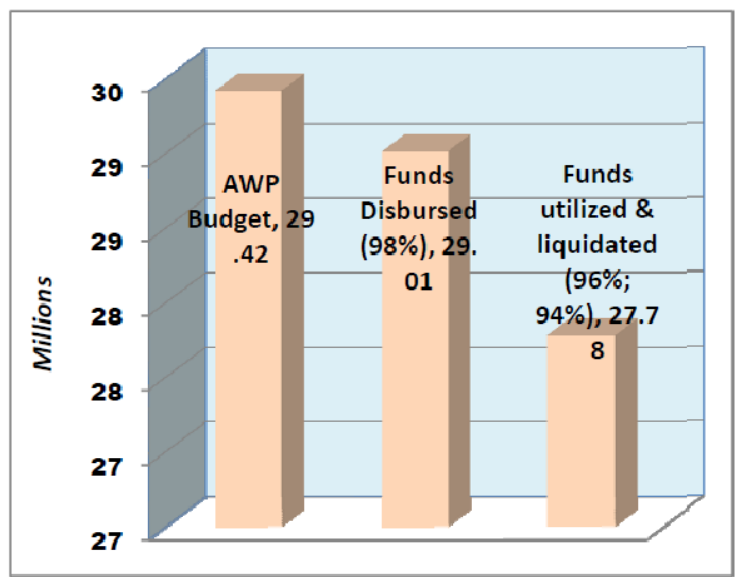

Figure 4. 3: MAGGA - Financial Implementation Status - UNFPA Funds 2014 Source: UNFPA Annual review meeting presentation

The figure 4. 3 above demonstrates that the NGO was being guided by its annual work plan budget when implementing its programs. Out of the disbursed funds, the NGO utilized $94 \%$ of the funds and this represent high implementation rate. The information in figure 4. 3 above, agree with León(2001 who suggests that the facial sustainability of an organization relies on strategic and financial planning and found administration and finance (p. 16) Furthermore, (Kotloff \& Burd, 2012, p10) noted that a complete understanding of all costs is critical to good fiscal management but budgets used to be based on accurate information about the organization's programs and services. This statement and many more observation of past research, confirms the importance of planning and budgeting for an NGO to successfully implement its planned programs.

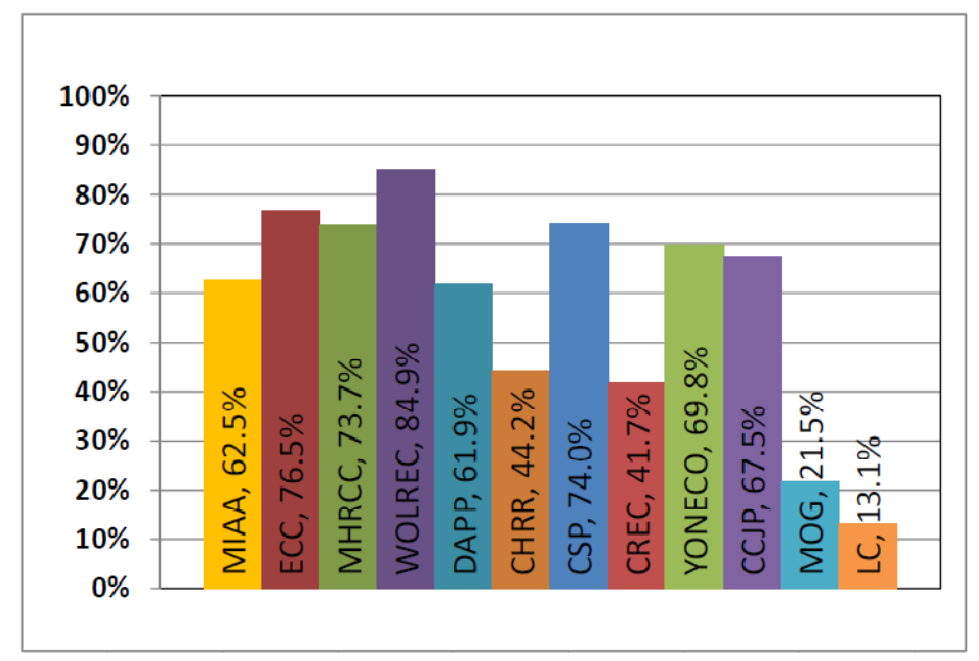

Figure 4. 4: Implementation Rate incl. of unliquidated funds for different NGOs Source: UNFPA Annual Review meeting Presentation

The figure above shows that some NGOs implementation rate was below $15 \%$. The low implementation rate by some NGOs could be as a result of absence of the six financial health management practices which are also worth investigation. During the UNFPA annual review meeting held in Blantyre Malawi in December, 2014 implementing partners revealed that late funding contributed to the poor implementation rate of their NGOs. For instance funding for second quarter April to June, 2014 was given in the third quarter around July and September, 2014 at a time the NOs were supposed to be implementing third quarter activities. Furthermore, it was discovered that some NGOs implemented the activities but reports were not submitted to the donors. When asked why the reports were not submitted on time, the workshop note $d$ that staff turnover especially in the accounts 
department and program staff contributed to the late submission of reports this affected mainly programs implemented by government since accounts staff in government can be transferred to any department or ministry at any time. Besides that, the donor observed that some implementing partners submitted poor reports which were turned to the NGO for correction. In the same vein, some reports contained expenses not related to the program activities which were not even in the annual work plan budget and were included on expenses reported to the donor which were disallowed. These sentiments and many more contributed to low implementation rate. Good financial accountability limits fraud and mismanagement and attracts donor interests- Furthermore, Leat (1988), adds accountability with sanctions, where some form of penalty should be imposed if the account or the actions are inadequate.

Marshall (2002), also adds that the most obvious way to ensure that NGOs are transparent is a full disclosure about their activities, which will enhance public trust. To agree with Leat (1988) and Marshall(2002) above, the donor has stopped funding some implementing partner directly, instead the donor is making direct payment to service providers although the activities are being implemented by some NGOs or government implementing partner as a form of penalty or risk management step to minimise financial risks.

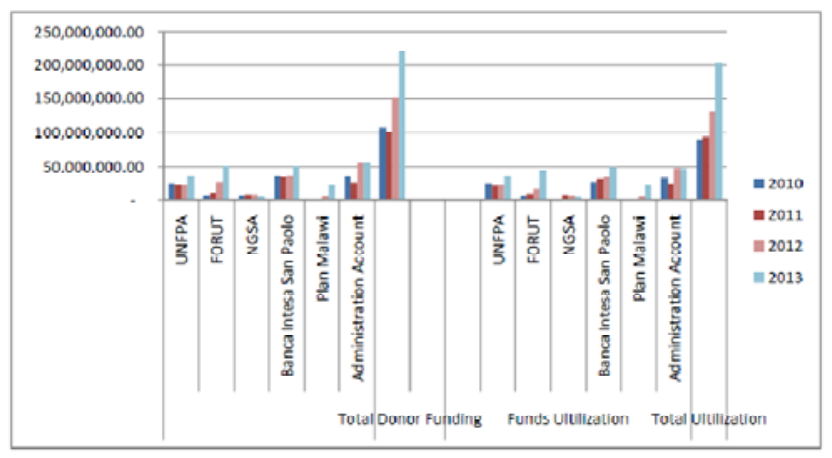

Figure 4. 5: MAGGA Funding and Funds Utilization 2010 -2013 Source: Primary data

The figure 4. 5 above shows that the NGO funds utilization rate was very high for all the four years under review. This high utilization rate is a result of good financial management practices demonstrated in table 4. 2 where the summary of the score shows existence of good financial health practices.

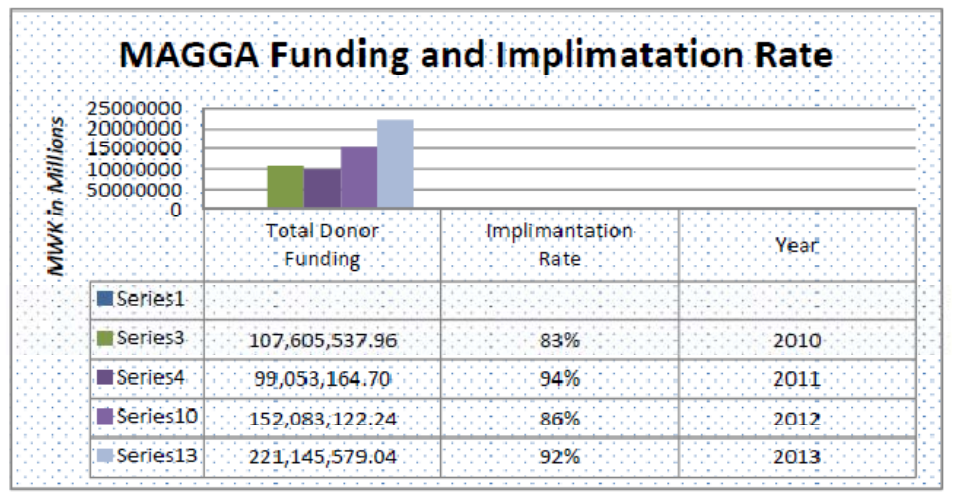

Figure 4. 6: MAGGA Implementation Rate for its donors $2010 \square 2013$

Source: Primary data

Figure 4. 6 above summarises the total donor funding for the years 2010 to 2013 for the NGO. The analysis reveals that the NGO implementation rate from 2010 to 2013 was above $83 \%$ and in 2011 the NGO implementation rate was as high as $94 \%$. This is as result of good financial health management practices of the organization. This confirms that there is a strong relationship between financial health management practices and program implementation rate. 
The strength of this NGO is the fact that it has scored well in all the six sections. On the one hand, it was observed in this research that the effects of good financial health management practices affect the overall performance of the $\mathrm{NGO}$ as all the six variables are equally important in program implementation. Interviews with the case study NGO showed that it valued the skills and exposure that come with donor-aided projects and that the projects had significantly contributed to the development of human resources within the NGO through on the job training supported by the donors as part of capacity building. This research has therefore established that there is a relationship in financial health management practices and implementation rate.

\section{Discussion of research findings, conclusion and recommendations}

\section{Introduction}

This chapter presents a summary of some of the key findings discussed in chapter four in relation to the objectives of the study and there view of the related literature.

The chapter is divided in four sections. The first section discusses the relationships between the variables. The second section suggest for further research, the third is a conclusion and the forth makes recommendations.

\section{Discussion of findings}

The objective of the study was to establish the relationship between financial health management practices and implementation rate. The analysis of the data obtained from the study summarised in table 4. 2 and relevant graphs, indicated that a strong positive relationship existed between financial health management practices which include budgeting and planning, internal control system, accounting system, grant management, financial reports, staffing and the NGO program implementation rate. This implies that if the overall financial health management practices of an NGO are strengthened will improve program implementation rate, leading to improved financial accountability, transparency and reduced financial risk which will win donor confidence for sustainable funding.

Contrary to the expectation of the researcher, the research has further established that donors also contribute to poor implementation rate by late funding the NGOs supplemented by lack of program monitoring and spot check visits. This give room to the NGOs to use donor funds in activities not covered in the agreed annual work plan with the donor and create challenges to submit timely reports. Donors further contribute to poor implementation rate by not providing capacity building to the NGOs through organised training especially for new staff on their reporting requirements. These are the major constraints the NGOs face when implementing donor funded programs.

\section{Relationship between budgeting/planning and implementation rate}

The analysis of the results on budgeting and Planning in figure 4. 2 and 4. 3 has established the strong relationship that exist between good budgeting and planning with the implementation rate in figure 4. 6 where the NGO achieved over 83\% through 2010 to 2013. Analysis of the results in figure five has established that the NGO has financial practices which are rigorous and the budget has significant detail and trend data by donor. The NGO engages donors directly to monitor accountability through spot checks and program monitoring in addition to the annual audit, which permits for direct oversight and deeper, more devoted partnerships with the donor. This is a smart financial practice as well as an excellent stewardship strategy which has contributed greatly for the NGO to achieve high implementation rate of above $83 \%$.

\section{Relationship between basic accounting system and implementation rate}

On accounting system, the study findings as seen in table 4. 2 support the relationship between accounting system and the implementation rate. According to the results show that the NGO has basic accounting system in place and scored 51 on this section which means that the NGO has a high level of integration of financial health management practices in this area which is in conformity with Schnelder (1989) who stresses that the heart of fiscal management in any organization is a good 
accounting system that is appropriate to that organization. This means that in order to achieve high implementation rate, it is necessary to establish standards and a system for accounting practices.

\section{Relationship between financial reporting and implementation rate}

In the section of financial reporting, analysis has shown that the NGO scored 29 which show that the NGO has a medium level of integration of financial management practices in this section. This confirms the assertion of (Sioan, 2001) who argued that the financial report is the first source of independent and true communication about performance of company managers. Cohen, Krisnamoorthy and Wright, 2004 added that one of the most important functions of corporate governance is to ensure the quality of financial reports.

Furthermore Gale (2003), observed that poor quality of financial reports greatly diminishes the quality of NGOs and he further noted that integrity of the non-profit sector is served best if NGOs are accountable. (Gale, 2003). This statement and the research findings together with the outcome of UNFPA annual review report confirms how financial reports directly affects implementation rate.

Furthermore, Keating and Frumkin (2003), agree with the above findings and comments that in order to determine the effectiveness of a financial reporting system, one must understand its objectives. Poor results in this section could lead to misunderstandings and conflict with donors on financial accountability. (Terry Lewis, 2013) assets that financial reports have to be read alongside narrative reports, so that you can build up a picture of what has been achieved with funds and whether it seems to represent good value for money

\section{Relationship between internal control and implementation rate}

On internal control, the results show that the NGO scored 73 in this section which was the highest score compared to other sections. According to (HACT frame work 2014), noted that a developed financial management system and control framework with a moderate likelihood of negative impact on the implementing partner's ability to execute the programme in accordance with the work plan. This means that an NGO with developed financial management will be able to implement its planned programme. This statement is supported by (Collier et al. , 2007) who observed that risk management is viewed as a corner stone of good corporate governance and therefore results in better service delivery, more efficient and effective use of scarce resources and better project management. The assertion of (Collier et al. , 2007) and the research findings convinced the researcher to conclude the existence of the relationship between internal control and implementation rate.

\section{Relationship between grant management and implementation rate}

On grant management, the research noted that an NGO which comply with grant agreement will likely manage to implement its planned activities without conflicts with donors. The research revealed that grant agreement contains a number of grant conditions, including procurement rules and reporting requirements. MAGGA work with five donors since 2010 and there is a signed grant agreement in place for each grant. The research further revealed that the NGO submits financial reports in the right format and on time. The research noted further that MAGGA keep track of which donor is funding which project (or part of a project) and it avoids borrowing money received from a donor for a specific project for another purpose. This confirms that an NGO to successfully implement its programme, it has to comply with the grant agreement.

\section{Relationship between staffing and implementation rate}

The research has managed to prove that good financial management is dependent on staff with the right skills, support, and attitude to carry out their responsibilities. All staff has a role to play in financial management. The scoring of the questionnaire revealed that MAGGA has staff with required qualification and skills and work as a team in achieving the NGO objectives which has resulted achieving over $83 \%$ implementation rate since 2010 to 2013 as seen in figure 4 . 6 . This concludes that integrating good financial management in to programs involves budget holders and finance staff working hand in hand through all the stages of the financial cycle. Furthermore (Kotloff \& Burd, 
2012, p. 10) observed that having appropriate software and trained staff helps to reduce inefficiencies and generate more accurate and reliable financial information.

\section{Conclusion}

This research has achieved the research objectives and the key research questions were answered and therefore make the following conclusions. The findings imply that high implementation rate of an NGO can be greatly improved if all the six variables discussed in this paper together with intervening variables are strengthened. The research has disclosed that capacity building, quarterly program monitoring and spot check including auditing mitigates financial risk and facilitate program implementation rate.

The analysis of the results further concluded that there is indeed a strong relationship between financial health management practices and implementation rate. It further revealed that though the financial health management practices facilitate high implementation rate, donors should also respect grant agreement and annual work plan on funding schedules as late funding affect timely reporting and implementation rate. This shows that donor aided projects designed and implemented by NGOs are often influenced by donor's policy objectives with less consideration of the challenges the NGO face in implementing the programs. The research findings has managed to confirm past research results on the same area as demonstrated in the literature review and several examples given in the discussion of the research results.

\section{Recommendations}

Below are some of the recommendations drawn from the discussion and analysis of the research findings. The recommendation are structured and directed to the NGO and the donors. As a result of this research the author has recommended for further research in the same area.

\section{Recommendation to the NGO}

The management of the NGOs are encouraged to make sure that the culture of financial health management practices stays embedded in their NGO. This can be achieved if the NGO make sure that new staff receive regular training and financial information and this can also be supplemented by donor support through capacity building, spot checks and regular program monitoring.

NGOs must use these financial health practices to link financial resources and programming with the needs of the donor and chart compliance with governance issues. Each NGO should view financial health management practices as one that needed often in order to better understand the value it is providing to the NGO and in order to build a strong case for support from donors as observed by Marilyn (2004), who observed that an explicit governance structure is the first step

toward establishing a stable and predictable framework for accountability in an NGO. However, in order to yield positive results the process of strengthening these variables by the NGO should be continuous. Finance, operations and program staff should work together towards the same goal and each side needs to understand how their roles are both important to achieving the NGO's mission so that they are bound together as a strong united team rather than working in silos.

\section{Recommendation to the donor}

The donors late funding contributed to the poor implementation rate and donors are encouraged to disburse funds to NGOs as per agreed annual work plan and based on the NGO capacity. Furthermore, the donors should intensify assurance activities like quarterly program monitoring and spots checks and audit to discover and address bottle necks which affect project implementation and associated challenges the NGO is facing. Donors should also continuously give capacity building support to NGO to train them on procurement, reporting and other donor requirements. Donor funding per quarter is a good practice and donors should desist from funding an NGO before liquidating the first or previous funding or advance to mitigate financial risks. UN agencies with NGO implementing partners are encouraged to comply with HACT framework 2014 procedures as it is intended to serve as a simplified set of procedures on requesting, disbursing, providing assurance, and reporting on 
funds as a way to effectively manage risks, reduce transaction costs and promote sustainable development in a coordinated manner by carrying micro assessment risk rating.

\section{Further research}

Similar study to be done on the same topic with more NGOs and statistical tools for analyzing results should be included beside the current tools used by the author.

Although the article offers well-supported arguments it has to be admitted that the current study is still far from being conclusive as observed in the discussion of results. Further studies must be undertaken, better measures must be developed, and larger samples from different NGOs must be used to improve our understanding on how the financial health management practices affect implementation rate. There is data gap which future research should address.

\section{References}

[1.] Terry Lewis, (2013). Mango Management Accounting for Non-governmental Organisations.

[2.] John L. Colley, JR. , Jacqueline L. Doyle, George W. Logan, \& Wallace Stettinius (2003) Corporate governance McGraw-Hill, Executive MBA Series

[3.] (HACT frame work 2014), Accessed on 28 April 2015 at www.gnhc.gov.bt/wpcontent/uploads/2012/12/BHUTAN-HACT-REFERENCE

[4.] CIPFA 2013, "Managing Organizations Published by CIPFA Education and training Centre" http://www. cipfa. org/cetc

[5.] Mango's Guide to financial management for NGOs. Accessed on 10 February 2015 at http://www. mango. org. uk/guide/fmincontext

[6.] Magala, C. (2001 ). Management of change in tertiary institutions: The case of Makerere University.

Makerere University:

[7.] Harvey, B. H. \& Sorkin, H. L. (1988). "Nonprofit accounting and financial reporting. " In T. D. Connors

(Ed. ). Then on profit organization handbook. New York: McGraw-Hill, Inc.

[8.] CPA Australia (2011)published by CPA Australia Ltd

[9.] COSO. (1998). Internal Control Integrated Framework. Report of the committee of sponsoring

Organizations of Trade way Commission, Jessey: American Institute of CPA. Light Paul C. (2002), Pathways to Nonprofit Excellence. Brookings Institution Press

[10.] Alan Fowler and Rick James, 1994. The role of Southern NGOs in Development Cooperation; occasional paper series\#2:INTRAC

[11.] Hope K. (2002), “The New Public Management: A Perspective from Africa”, in K. Mc Laughin, S.

Osborne and E. Feline (Eds), New Public Management: Current trends and Future Prospects: London:

Routledge

[12.] Alan Fowler, 1999. Distant obligations: speculations on NGO funding and the global market: University of Sussex, Brighton, UK

[13.] Marshall M. (2002), Legitimacy and Effectiveness: Civil Society Organizations' Rolein Spillane, J. P. \&

Relmer, T. (2000). "Policy Implementation and Cognition: Reframing and Refocusing Implementation

Research", Review of Education Research, Vol. 72, No. 3 pp 387 - 431.

[14.] Good Governance, Paper presented at the Poverty Reduction Strategies Forum, Austria, October 29November 1, 2002.

[15.] Tvedt, T. (1998). Angels of mercy or development diplomats? NGOs and foreign aid. Trenton: African World Press

[16.] Cohen J. (2003), Governance by and of NGOs, Institute of Social and Ethical Accountability, UK. Cohen, Krisnamoorthy and Wright (2004), The Corporate Governance Mosaic and Financial Reporting Quality, Journal of Accounting Literature, Vol. 23, pp 87- 152.

[17.] CPA Australia Internal controls for not-for-profit organisations-cpaaustralia.com. au Fowler A. (2000), "Relevance in the Twenty-first Century: The Case for Devolution and Global Association of International NGOs" in D. Eade (Ed).

[18.] León, P. (2001 ). Four Pillars of Financial Sustainability. The Nature Conservancy(2), 4-29

[19.] Keating, Elizabeth \& Frumkin (2003), Re engineering Nonprofit Financial Accountability: Towards a More Reliable Foundation for Regulation, Journal of Public Administration Review, Vol. 63, No 1 pp 3-15. 
E-International Journals of Academic Research

Volume 3, Issue 1, 2016

[20.] Moore, M. H. (2000). Managing for value: organizational strategy in for-profit, nonprofit, and government organizations. Nonprofit and Voluntary Sector Quarterly, 29(1), 183-204.

[21.] Leat, D. (1988), Voluntary Organizations and Accountability, Worcester, UK. , Policy Analysis Unit, National Council for Voluntary Organizations.

[22.] Morris, M. H. , Coombes, S. , \& Schindehutte, M. (2007). Antecedents and outcomes of entrepreneurial and market orientation in anon-profit context: Theoretical and empirical insights. Journal of Leadership \& Organizational Studies, 13(4), 12-39

[23.] Brody, E. (2001), Accountability and Public Trust, in the state of America's Non profit sector, Aspen Institute and Brookings Institution

[24.] Kotloff, L. J. \& Burd, N. (2012). Building stronger non profits through better financial management: Early efforts in 26 youth-serving organizations. Public/Private Ventures, The Wallace Foundation

[25.] Murray, Bradshawand Wolpin (1992), Do Non profits Boards make a difference? An exploration of the relationships among the board structure, process and effectiveness, Nonprofit and Voluntary Sector Quarterly. [26.] Bezjian, J. , Holmstrom, W. , Kipley, D. (2009). Creating not-for-profit organizational legitimacy during periods of economic constraints and diminishing donor resources. The Business Renaissance Quarterly, 4(4), 49-67.

[27.] Kogan M. (1986), Education Accountability: Ananalytical overview, London Hitchinson. Keating, Elizabeth \& Frumkin (2003), Assessing Non-Profit Making Financial Measures, Accountability and Evaluation, Non-Profit Sector Research Fund

[28.] Harris M. (1996), "Dowe need Governing Bodies?” in D. Billisand M. Harris (Eds)Voluntary Agencies: Challenges of Organization and Management.

[29.] Eyong T. O. (2001), Promoting Good Governance in the Management of NGOs.

[30.] Gale L. C. (2003), Califonia Non-profit Quality Reporting Project, Retrieved 15 August 2004.

[31.] Boice, J. (2004), The Accountability, Accessed on 10 May 2015 at

www.afpet.org/contentdocuments/marap04cover.pdf

[32.] Ebrahim, Alnoor, (2003), Accountability in Practice: Mechanisms for Donor NGOs, World Development, Vol 394. 